\title{
A molecular (NCS2)Ni(II) electrocatalyst resembles [NiFe]hydrogenase pathway for $\mathrm{H}_{2}$ evolution
}

Soumalya Sinha, ${ }^{, ; \#}$ Giang N. Tran, ${ }^{\prime, \#}$ Hanah Na, ${ }^{\dagger}$ and Liviu M. Mirica ${ }^{\dagger, *}$

${ }^{\dagger}$ Department of Chemistry, University of Illinois at Urbana-Champaign, 600 S. Mathews Avenue, Urbana, Illinois, 61801

\# These authors contributed equally.

*e-mail: mirica@illinois.edu

KEYWORDS: Electrocatalysis, hydrogen evolution reaction (HER), Ni(I) complexes, organometallic Ni complexes, hydrogenase, bioinspired catalysts 


\section{ABSTRACT}

The electrochemical hydrogen evolution reaction (HER) is considered a sustainable energy approach to advance fuel-cell technologies, and HER electrocatalysts that resembles the [NiFe] hydrogenases are highly desired. Herein, we report a bioinspired Ni(II) complex (NCHS2)Ni(OTf)2, where NCHS2 is 3,7-dithia-1(2,6)-pyridina-5(1,3)-benzenacyclooctaphane, that is an efficient electrocatalyst for HER with turnover frequencies up to $400,000 \mathrm{~s}^{-1}$ in the presence of low acid concentration, and compares favorably with the other reported Ni HER electrocatalysts. Importantly, in this complex the rationally designed NCHS2 ligand undergoes C$\mathrm{H}$ bond activation and the resulting organometallic Ni-aryl complex restricts the formation of a $\mathrm{Ni}(0)$ species, which resembles the role of the cysteine ligands in [NiFe] hydrogenases. In addition, this electrocatalyst follows a unique HER mechanism via detectable $\mathrm{Ni}(\mathrm{I}) / \mathrm{Ni}$ (III) intermediates that are also proposed for $[\mathrm{NiFe}]$ hydrogenases, yet such a mechanism has not been observed to date in model systems. 


\section{Introduction}

Fuel cell technologies employing hydrogen $\left(\mathrm{H}_{2}\right)$ are promising in the search for sustainable and renewable energy resources to replace fossil fuels, ${ }^{1,2}$ however the production of $\mathrm{H}_{2}$ with high turnover frequencies (TOFs) using earth-abundant molecular catalysts under benign reaction conditions is still a challenge. ${ }^{3-8}$ In Nature, [NiFe] hydrogenases perform the $\mathrm{H}_{2}$ evolution reaction (HER) reversibly with TOFs of up to $\sim 1000 \mathrm{~s}^{-1}$ in weakly acidic aqueous solutions at very low overpotential. ${ }^{9-12}$ For these enzymes, the proposed mechanism involves key reactive intermediates, termed the Ni-L, Ni-C, and Ni-R states, which control the proton and electron transfer steps (Figure 1a). ${ }^{13-21}$ These intermediates have been the inspiration for designing electrocatalysts for the HER or $\mathrm{H}_{2}$ oxidation reactions, yet very few examples of bioinspired $\mathrm{Ni}$ catalysts that were successfully incorporated in practical fuel cells are known. ${ }^{22,23}$

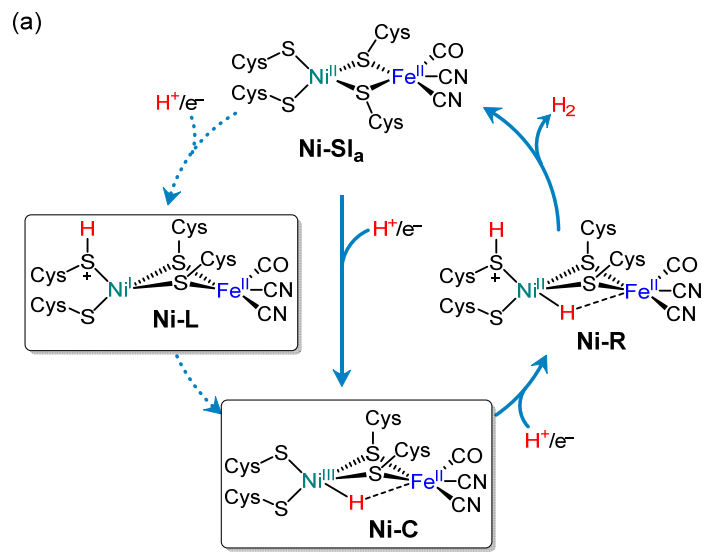

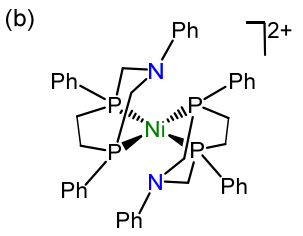

$\left[\left(\mathrm{NP}_{2}\right)_{2} \mathrm{Nij}\right]^{2+}$

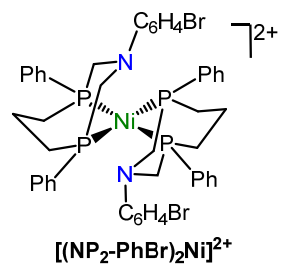

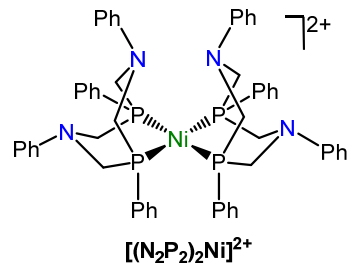

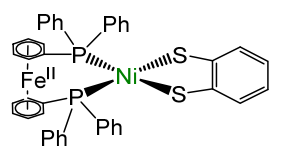

$\left(\mathrm{S}_{2} \mathrm{P}_{2}\right) \mathrm{Ni}-\mathrm{FeCp}_{2}$

Figure 1. (a) Catalytic HER cycle promoted by [NiFe] hydrogenases. The paramagnetic Ni-L and $\mathrm{Ni}-\mathrm{C}$ intermediates are highlighted, and the formation of the Ni-L intermediate is shown with dotted arrows. ${ }^{12}$ (b) Selected Ni-based molecular electrocatalysts reported for efficient HER electrocatalysis: (NP2) ${ }_{2} \mathrm{Ni}^{24}(\mathrm{~N} 2 \mathrm{P} 2)_{2} \mathrm{Ni}^{25}{ }^{25}(\mathrm{NP} 2-\mathrm{PhBr})_{2} \mathrm{Ni},{ }^{26}$ and $(\mathrm{S} 2 \mathrm{P} 2) \mathrm{Ni}-\mathrm{FeCp} 2 .{ }^{27}$ 
Many molecular Ni-based electrocatalysts carrying proton relay group(s) in the secondcoordination sphere have been investigated. ${ }^{24,26,28-31}$ For example, $\left[\left(\mathrm{NP}_{2}\right)_{2} \mathrm{Ni}\right]^{2+}$ and $\left[\left(\mathrm{NP}_{2}-\right.\right.$ $\left.\mathrm{PhBr}{ }_{2} \mathrm{Ni}\right]^{2+}$ (Figure 1b) catalyze HER in MeCN with TOF of $100,000 \mathrm{~s}^{-1}$ and $800 \mathrm{~s}^{-1}$, respectively, using protonated dimethylformamide, $[(\mathrm{DMF}) \mathrm{H}]^{+}\left(\mathrm{p} K_{\mathrm{a}[(\mathrm{DMF}) \mathrm{H}]}=6.1\right)^{32}$ and $\mathrm{H}_{2} \mathrm{O}$ as proton sources. ${ }^{24,26}$ Furthermore, Dempsey and co-workers reported the detailed investigation of the electrocatalytic HER mechanism using $\left[\left(\mathrm{N}_{2} \mathrm{P}_{2}\right)_{2} \mathrm{Ni}^{2+}\right]^{2}$ (Figure 1b) as the catalyst and anilinium as the proton source in $\mathrm{MeCN}\left(\mathrm{p} K_{\mathrm{a}, \text { anilinium }}=10.62\right) .{ }^{25,32}$ An example of a bimetallic NiFe complex bearing a S2P2 ligand, $\left(\mathrm{S}_{2} \mathrm{P}_{2}\right) \mathrm{Ni}-\mathrm{FeCp} 2$ (Figure 1b), was reported as a bioinspired synthetic model that exhibits electrocatalytic HER at an overpotential of only $265 \mathrm{mV}$ in the presence of acetic acid $(\mathrm{AcOH})$ in THF $\left(\mathrm{p} K_{\mathrm{a}, \mathrm{AcOH}}=22.48\right)$, but with a low TOF $\left(1,240 \mathrm{~s}^{-1}\right) \cdot{ }^{27}$ Therefore, performing HER with high TOF using a low concentration of a weak acid is still challenging despite its thermodynamic simplicity.

Herein, we report a bioinspired $\mathrm{Ni}^{\mathrm{II}}$ complex, $(\mathrm{NCHS} 2) \mathrm{Ni}(\mathrm{OTf})_{2}\left(\mathbf{1}(\mathbf{O T f})_{2}\right.$, Figure 2a), where NCHS2 is 3,7-dithia-1(2,6)-pyridina-5(1,3)-benzenacyclooctaphane. Excitingly, complex 1 catalyzes HER with TOF up to $400,000 \mathrm{~s}^{-1}$ at an overpotential of $490 \mathrm{mV}$ in the presence of a low concentration $(\leq 0.043 \mathrm{M})$ of trifluoroacetic acid (TFA, $\left.\mathrm{p} K_{\mathrm{a}}=12.65\right),{ }^{32,33}$ with $\geq 1 \mathrm{M}$ of added $\mathrm{H}_{2} \mathrm{O}$ in MeCN. Furthermore, $\mathbf{1}$ is also an active HER electrocatalyst with a TOF of $\sim 2,000 \mathrm{~s}^{-1}$ in the presence of a low concentration $(\leq 0.05 \mathrm{M})$ of $\mathrm{AcOH}$ in $\mathrm{MeCN}$. A comparative catalytic Tafel plot was employed to benchmark the kinetic and thermodynamic properties of $\mathbf{1}$ vs. the previously reported Ni-based HER electrocatalysts, revealing that 1 compares favorably with the other reported Ni systems.

Importantly, in complex 1 the rationally designed NCHS2 ligand undergoes $\mathrm{C}-\mathrm{H}$ bond activation and the resulting organometallic Ni-aryl complex is proposed to restrict the formation 
of a $\mathrm{Ni}(0)$ species, which is a novel idea in biomimetic systems and resembles the role of the cysteine ligands in $[\mathrm{NiFe}]$ hydrogenases. In addition, this electrocatalyst follows a unique HER mechanism via detectable $\mathrm{Ni}^{\mathrm{I}} / \mathrm{Ni}^{\mathrm{III}}$ intermediates that are also proposed for $[\mathrm{NiFe}]$ hydrogenases, yet such a mechanism has not been observed to date in model systems. Electron paramagnetic resonance (EPR) spectroscopy was used to detect and probe such $\mathrm{Ni}^{\mathrm{I}}$ and $\mathrm{Ni}^{\mathrm{III}}$ species, further supporting the proposed $\mathrm{Ni}^{\mathrm{I}} / \mathrm{Ni}^{\mathrm{III}} \mathrm{HER}$ mechanism. Overall, we consider that this new bioinspired, constrained geometry HER electrocatalyst will set up a new platform for designing and implementing molecular catalysts that are more biomimetic and can efficiently produce $\mathrm{H}_{2}$, a key ingredient in fuel cells.
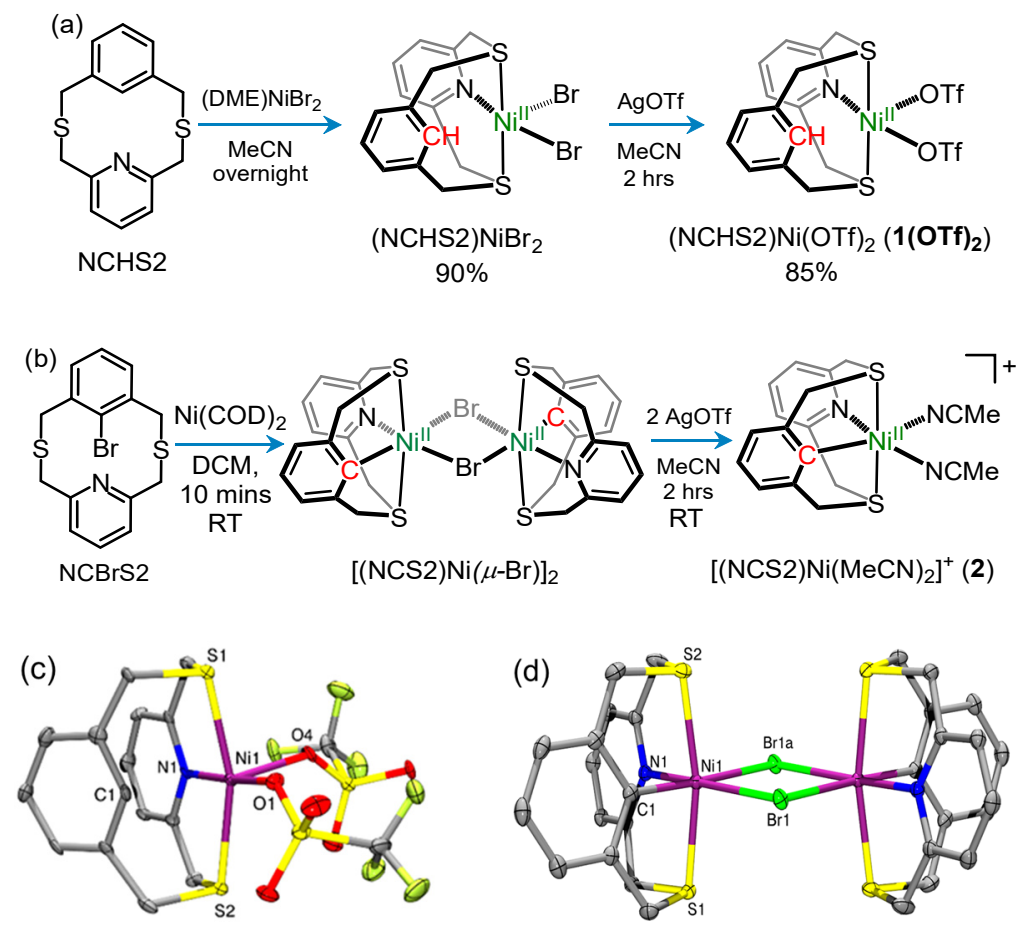

Figure 2. (a) and (b) Synthetic schemes for (NCHS2)Ni(OTf) $)_{2} \quad\left(\mathbf{1}(\mathbf{O T f})_{2}\right)$ and $\left[(\mathrm{NCS} 2) \mathrm{Ni}(\mathrm{MeCN})_{2}\right]^{+}(2)$, respectively. ORTEP representations $(50 \%$ probability ellipsoids) for $\mathbf{1}(\mathbf{O T f})_{2}(\mathrm{c})$ and $[(\mathrm{NCS} 2) \mathrm{Ni}(\mu-\mathrm{Br})]_{2}(\mathrm{~d})$. Selected bond distances $(\AA)$ and angles $\left({ }^{\circ}\right)$ for 1(OTf $)_{2}$ : Ni1-N1 2.001(6), Ni1-O4 2.039(5), Ni1-O1 2.043(4), Ni1-S1 2.391(2), Ni1-S2 2.407(2), Ni1- 
C1 2.478(8), N1-H1 2.299, N1-H1-C1 89.61, and [(NCS2)Ni( $\mu-\mathrm{Br})] 2$ : Ni-N1 2.042(1), Ni-C1 1.980(1), Ni-S1 2.3759(5), Ni-S2 2.3899(5), Ni-Br1 2.5487(4), Ni-Brla 2.720(4).

\section{Results}

Synthesis and characterization. The newly developed NCHS2 ligand was reacted with (DME)NiBr2 and subsequent addition of 2 equiv AgOTf yielded the desired complex 1(OTf $)_{2}$ as a green solid in $85 \%$ yield (Figure 2). Notably, $\mathbf{1}(\mathbf{O T f})_{2}$ can also be synthesized in a one-step procedure by reacting $\mathrm{NCHS} 2$ with 1 equiv of $\mathrm{Ni}(\mathrm{OTf})_{2}$ in $\mathrm{MeCN}$ and toluene, respectively, although a slightly lower yield $(60 \%)$ was obtained. The X-ray crystallographic data of $\mathbf{1 ( O T f})_{2}$ reveals a distorted square pyramidal geometry at the $\mathrm{Ni}$ center, with one triflate ligand found in the axial position, while the other triflate ligand, the $\mathrm{N}$ atom, and the two $\mathrm{S}$ atoms of NCHS2 occupy the equatorial positions (Figure $2 \mathrm{c}$ ). Interestingly, a $\mathrm{Ni} \cdots \mathrm{H}-\mathrm{C}_{\text {aryl }}$ interaction was observed for 1, with Ni1-C1 and Ni1-H1 distances, $2.478 \AA$ and $2.299 \AA$, respectively, and a Ni1-H1-C1 angle of $89.61^{\circ}$, and these metrical parameters suggest an anagostic interaction between the $\mathrm{Ni}$ and the $\mathrm{C}_{\mathrm{ipso}}-\mathrm{H}$ bond. This is similar to what was observed previously for related Ni-pyridinophane complexes, in which $\mathrm{C}_{\mathrm{ipso}}-\mathrm{H}$ bond activation was observed upon oxidation. ${ }^{34}$

Given the susceptibility of the $\mathrm{C}_{\mathrm{ipso}}-\mathrm{H}$ bond in NCHS2 to be activated during redox transformations, we have independently synthesized the organometallic complex [(NCS2) Ni(MeCN) 2$](\mathrm{OTf}), 2(\mathrm{OTf})$, via a two-step procedure and starting with the $\mathrm{NCBrS} 2$ ligand

and $\mathrm{Ni}(\mathrm{COD})_{2}$ (Figure 2b). The intermediate species was analyzed via single crystal X-ray crystallography to reveal a dinuclear complex $[(\mathrm{NCS} 2) \mathrm{Ni}(\mu-\mathrm{Br})] 2$, which is proposed to yield $\mathbf{2}$ upon halide elimination using AgOTf (Figure 2d). The distance between the two Ni centers in $[(\mathrm{NCS} 2) \mathrm{Ni}(\mu-\mathrm{Br})]_{2}$ was found to be $3.869 \AA$, with no significant bonding interaction between the 
two Ni atoms (Figure 2d). The coordination geometry of both Ni centers is distorted octahedral, with two S atoms in the axial positions and the NCS2 ligand binding in a $\kappa^{4}$ conformation. The $\mathrm{Ni}-\mathrm{N} 1$ and average Ni-S bond distances are $2.042 \AA$ and $2.383 \AA$, respectively, while the Ni-C1 distance is significantly shorter than that in $\mathbf{1}(1.980 \AA$ vs. $2.478 \AA)$, as expected for the presence of a bonding interaction and similar to related organometallic Ni complexes. ${ }^{35}$

Electrochemical studies in the absence of an acid. The cyclic voltammogram (CV) of 1 shows a single cathodic wave at around $-1.5 \mathrm{~V}$, assigned to the $\mathrm{Ni}^{\mathrm{II}} / \mathrm{Ni}^{\mathrm{I}}$ reduction process, and a corresponding oxidation wave with similar peak current density at $\sim-0.26 \mathrm{~V}$ (Figures 3a and S9). Furthermore, the CVs of $\mathbf{1}$ recorded at different scan rates support a purely homogeneous electrochemical process (Figures $3 \mathrm{~b}$ and $\mathrm{S} 13$ ), ${ }^{36,37}$ and the peak potentials for the $\mathrm{Ni}^{\mathrm{II} / \mathrm{I}}$ reduction $\left(E_{\mathrm{Ni}^{\mathrm{II} / \mathrm{I}}}\right)$ at different scan rates shifted linearly with a slope of $61 \mathrm{mV}$ per decade (Figure $3 \mathrm{c}$ ), suggesting a Nernstian electron transfer step (E) for $\mathbf{1}$ followed by a chemical process (C). ${ }^{38-40}$ Interestingly, no additional reduction event suggestive of a $\mathrm{Ni}^{\mathrm{I}} / \mathrm{Ni}^{0}$ process was observed down to $-2.75 \mathrm{~V}$, suggesting that the $\mathrm{Ni}^{0}$ may not be easily accessible, and we posit that the observed $\mathrm{C}$ step may preclude the formation of $\mathrm{N}^{0}$ species (see below).

(a)

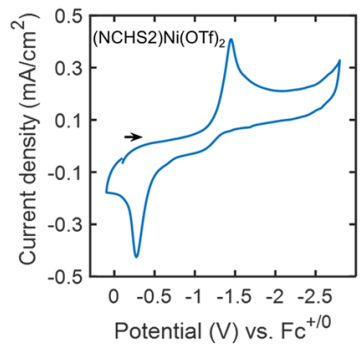



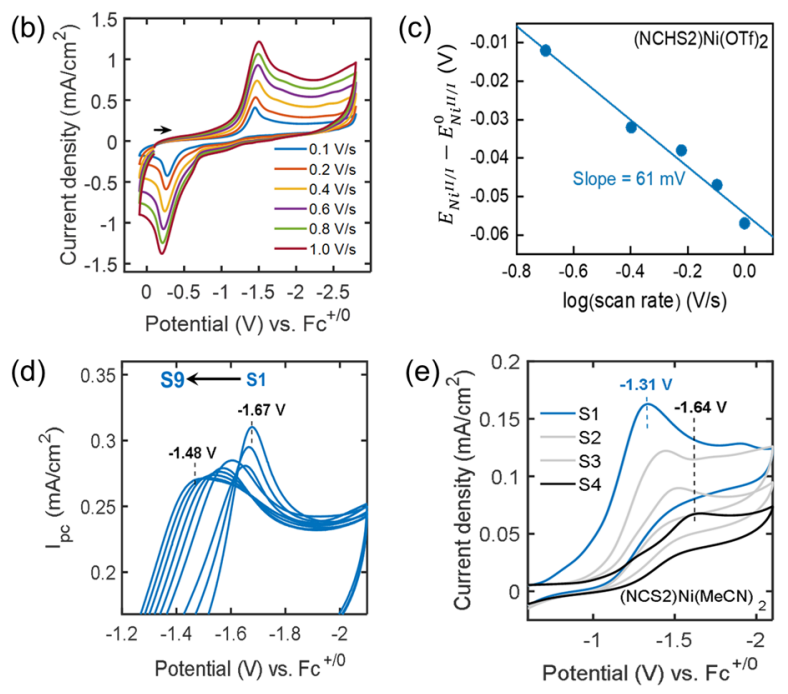

Figure 3. CVs recorded for 1 at (a) $0.1 \mathrm{~V} / \mathrm{s}$ scan rate and (b) different scan rates $(0.1 \mathrm{~V} / \mathrm{s}-1 \mathrm{~V} / \mathrm{s})$. (c) Peak shifts at $\mathrm{Ni}^{\mathrm{II} / \mathrm{I}}$ reductive waves obtained from (b) at different scan rates are plotted versus the logarithm of scan rates $(\mathrm{V} / \mathrm{s}) . E_{N i^{I I / I}}^{0}$ is the peak potential observed at the $\mathrm{Ni}^{\mathrm{II} / \mathrm{I}}$ cathodic wave at $0.1 \mathrm{~V} / \mathrm{s}$ scan rate. The $\mathrm{R}^{2}$ value for the linear fit is 0.98 . (d) CVs for 1 upon nine repeating CV sweeps. S1 and S9 indicate the first and ninth CV sweeps, and the black arrow shows the direction of the peak shift. (e) CVs for 2 upon four repeating CV sweeps. S1 (blue) and S4 (black) indicate the first and fourth $\mathrm{CV}$ sweeps. Only reductive waves for $\mathrm{Ni}^{\mathrm{II} / \mathrm{I}}$ redox couples are shown for clarity. All CVs were recorded in $\mathrm{N}_{2}$-saturated $0.1 \mathrm{M} \mathrm{TBAPF} / \mathrm{MeCN}$ solution.

Successive CV sweeps recorded for 1 reveal a shift of $E_{\mathrm{Ni}^{\mathrm{I}} / \mathrm{I}}$ toward higher potentials (approximately $+0.2 \mathrm{~V}$ after the ninth $\mathrm{CV}$ cycle, Figures $3 \mathrm{~d}$ and S10) that indicates a change in the redox properties of $\mathbf{1}$ upon repeating the CV sweeps. Given the EC electrochemical mechanism suggested by the variable scan rate CVs, we propose the following sequence of events: oneelectron reduction of $\mathbf{1}$ generates the $\mathrm{Ni}^{\mathrm{I}}$ species $\mathbf{3}$ (the E step), followed by a chemical (C) step that could be either an oxidative addition step to form a six-coordinate $\mathrm{Ni}{ }^{\mathrm{III}}-\mathrm{H}$ species $\mathbf{4}$, or a concerted metalation-deprotonation $(\mathrm{CMD})$ process $^{41}$ to form a square planar $\mathrm{Ni}^{\mathrm{I}}$ complex $\mathbf{5}$ (Figure 4), with species $\mathbf{4}$ and $\mathbf{5}$ being considered a tautomers of each other. subsequent redox step coupled with the loss of a proton (or hydride) would generate $\mathbf{2}$, and thus lead to a different $\mathrm{Ni}^{\mathrm{II}}$ complex after a complete CV cycle. 


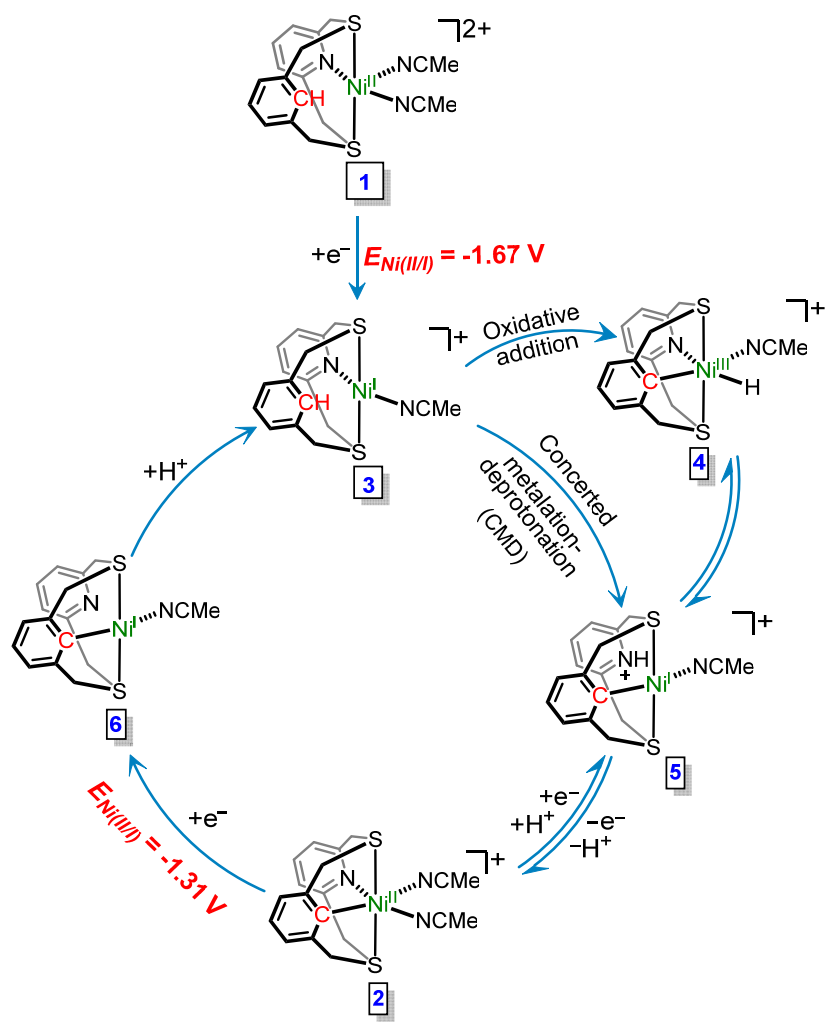

Figure 4. Proposed electrochemical events for 1 in $\mathrm{MeCN}$.

Interestingly, the $\mathrm{CVs}$ of $\mathbf{2}$ were recorded independently in $\mathrm{MeCN}$ and a reduction wave with $E_{\mathrm{Ni}} \mathrm{II} / \mathrm{I}$ was observed at $-1.31 \mathrm{~V}$ (first CV sweep, scan S1 in Figure 3e), which is at least 0.35 V more positive than the $E_{\mathrm{Ni}^{\mathrm{II}} / \mathrm{I}}$ for $\mathbf{1}$. Furthermore, repeating the $\mathrm{CV}$ sweeps for $\mathbf{2}$ revealed that the $E_{\mathrm{Ni}} \mathrm{I} / \mathrm{I}$ value moves toward lower potentials with a degradation of the cathodic peak currents (Figure 3e). Noteworthy, the $E_{\mathrm{Ni}}$ I/I observed for 2 after the fourth $\mathrm{CV}$ cycle appeared at $-1.64 \mathrm{~V}$ (scan S4 in Figure 3e), which matches the $E_{\mathrm{Ni}^{\mathrm{II}} / \mathrm{I}}$ of the first CV sweep obtained for $\mathbf{1}$ (scan $\mathrm{S} 1$ in Figure 3d). Therefore, we posit that during the CV scans, the reduction of $\mathbf{2}$ to $\mathbf{6}$ is followed by protonation of the Ni-C aryl bond by adventitious protons to generate $\mathbf{3}$ and ultimately $\mathbf{1}$ during the return oxidative CV scans (Figure 4). Such redox events that involve changes in the 
coordination environment of the Ni center could also support the large peak separations observed in the CVs of both 1 and 2 (Figure 3).

Electron paramagnetic resonance (EPR) studies. Since several intermediates present during HER electrocatalysis are proposed to be paramagnetic $\mathrm{Ni}^{\mathrm{I}} / \mathrm{Ni}^{\mathrm{III}}$ species, similar to the $\mathrm{Ni}-\mathrm{L}$ and $\mathrm{Ni}$ C states in [NiFe] hydrogenases (Figure 1a), we then performed EPR studies to probe any paramagnetic species formed upon the one-electron reduction of $\mathbf{1}$ or $\mathbf{2}$. Complex $\mathbf{2}$ was first reduced using 1 equiv $\mathrm{Co}^{\mathrm{II}} \mathrm{Cp} 2(\mathrm{Cp}=$ cyclopentadienyl), and the $\mathrm{X}$-band $\mathrm{EPR}$ spectrum of resulting solution at $77 \mathrm{~K}$ was simulated using two sets of rhombic g tensors ( $\operatorname{Sim} 1: \mathrm{g}_{\mathrm{x}}=2.246, \mathrm{~g}_{\mathrm{y}}=2.202$, $\mathrm{g}_{\mathrm{z}}=2.009$, and $\operatorname{Sim} 2: \mathrm{g}_{\mathrm{x}}=2.280, \mathrm{~g}_{\mathrm{y}}=2.085, \mathrm{~g}_{\mathrm{z}}=2.068$ ) in a 4:1 ratio, respectively (Figure 5a). Taken together, we posit that reduction of 1 generates two different paramagnetic species, in which species 3 could correspond to the Sim 1 EPR signal that exhibits superhyperfine coupling to $2 \mathrm{~N}$ atoms $\left(A_{\mathrm{z}}=11 \mathrm{G}\right)$ in the $\mathrm{g}_{\mathrm{z}}$ direction (Figure 5a), while the other lower intensity Sim 2 signal is tentatively assigned to either species $\mathbf{4}$ or $\mathbf{5}$, by comparing with the EPR spectra of other reported $\mathrm{Ni}^{\mathrm{III}}{ }^{42,43}$ or $\mathrm{Ni}^{\mathrm{III}}-\mathrm{H}$ complexes. ${ }^{21,44}$ Interestingly, a similar EPR spectrum, yet comprising the two sets of $\mathrm{g}$ tensors in a 10:1 ratio, was obtained upon treating 2 with 1 equiv $\mathrm{Co}^{\mathrm{II}} \mathrm{Cp} 2$ (Figures $5 \mathrm{~b}$ and S36). The larger fraction of the Sim 2 signal upon the reduction of $\mathbf{1}$ vs. the reduction of $\mathbf{2}$ could be due to the presence of the phenyl ipso proton in the NCHS2 ligand, while the reduction of the (NCS2) $\mathrm{Ni}^{\mathrm{II}}$ complex 2 would require the presence of adventitious protons, and thus suggesting that the $\operatorname{Sim} 2$ signal might correspond to a species that contains an extra proton (i.e., species 4 or 5, Figure 4). Thus, the chemical reduction of either $\mathbf{1}$ and $\mathbf{2}$ results in the likely formation of $\mathbf{3}$, along with another paramagnetic species that is tentatively assigned as either $\mathbf{4}$ or $\mathbf{5}$. While more detailed EPR studies are required to unambiguously identify these paramagnetic species, these studies clearly show that several $\mathrm{Ni}^{\mathrm{I}}$ and/or $\mathrm{Ni}^{\mathrm{III}}$ intermediates are formed during the reduction of 
either (NCHS2) $\mathrm{Ni}^{\mathrm{II}}$ and $(\mathrm{NCS} 2) \mathrm{Ni}^{\mathrm{II}}$ complexes. Further evidence that the NCS2 ligand system can support a $\mathrm{Ni}^{\mathrm{III}}$ center is provided by the oxidation of the $(\mathrm{NCS} 2) \mathrm{Ni}^{\mathrm{II}}$ complex 2 with 1 equiv $\mathrm{NOPF}_{6}$ to generate detectable $\mathrm{Ni}^{\mathrm{III}}$ species that can persist for several minutes at $\mathrm{RT}$, as observed by EPR (Figure S38).
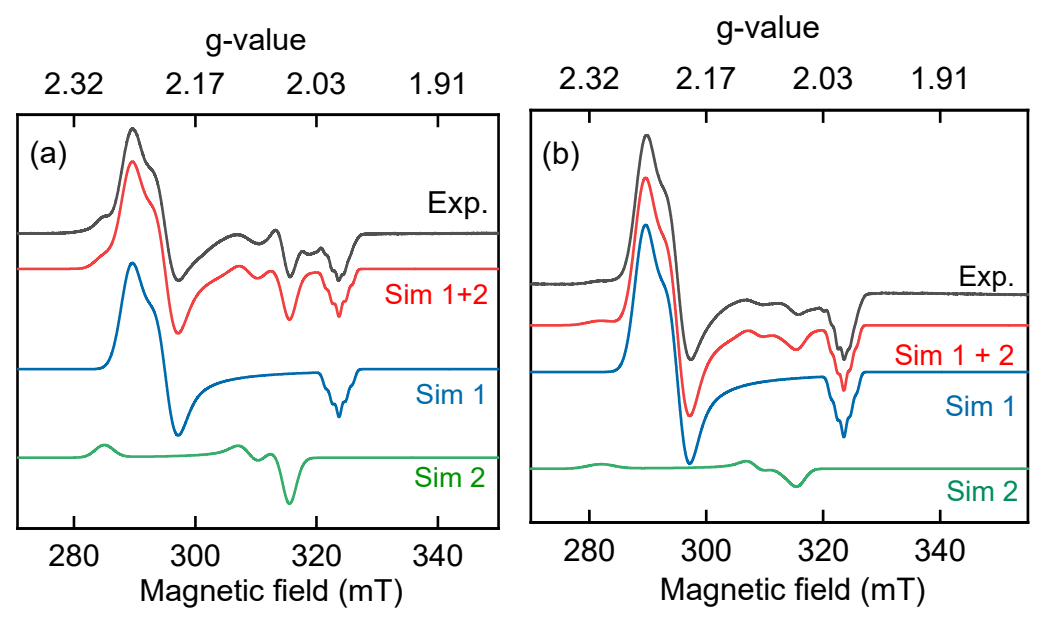

Figure 5. Experimental (black) and simulated (red) EPR spectra for (a) 1 and (b) $\mathbf{2}$ after treating with 1 equiv. of $\mathrm{Co}^{\mathrm{II}} \mathrm{Cp}_{2}$ in $\mathrm{MeCN} / \mathrm{PrCN}(1: 3)$ at $77 \mathrm{~K}$. For both cases, the simulated spectra (red) employed two sets of parameters, Sim 1 (blue) and Sim 2 (green). The following parameters were used for the simulations: (a) Sim 1: $g_{\mathrm{x}}=2.246 g_{\mathrm{y}}=2.202, g_{\mathrm{z}}=2.008\left(A_{2 \mathrm{~N}}=11 \mathrm{G}\right), \operatorname{Sim} 2: g_{\mathrm{x}}=$ $2.280, g_{\mathrm{z}}=2.085\left(A_{\mathrm{I}=1 / 2}=60 \mathrm{G}\right), g_{\mathrm{y}}=2.068\left(A_{\mathrm{I}=1 / 2}=10 \mathrm{G}\right)$; (b) Sim 1: $g_{\mathrm{x}}=2.246 g_{\mathrm{y}}=2.202, g_{\mathrm{x}}=$ $2.009\left(A_{2 \mathrm{~N}}=11 \mathrm{G}\right), \operatorname{Sim} 2: g_{\mathrm{x}}=2.305, g_{\mathrm{y}}=2.091\left(A_{\mathrm{I}=1 / 2}=50 \mathrm{G}\right) g_{\mathrm{z}}=2.069\left(A_{\mathrm{I}=1 / 2}=20 \mathrm{G}\right)$. The ratios of Sim 1 to Sim 2 for (a) and (b) are 4:1 and 10:1, respectively.

Electrochemical studies in the presence of an acid. Complex 1 performed electrocatalytic HER using $\mathrm{AcOH}$ in $\mathrm{MeCN}$ by exhibiting a current increase at potentials more negative than $-2.0 \mathrm{~V}$ (Figure 6d), yet the quasi-plateau currents at higher $\mathrm{AcOH}$ concentrations appeared at only 140 $\mathrm{mV}$ more positive potential than that of the direct proton reduction by the GC electrode (Figure S18), and thus a stronger acid, trifluoroacetic acid (TFA), was used in subsequent studies. The background proton reduction activity in the absence of $\mathbf{1}$ was first benchmarked at different concentrations of TFA ( $0 \mathrm{M}$ to $0.043 \mathrm{M}$, Figure S5), and two reductive waves were observed at 
potentials more negative than $-1.5 \mathrm{~V}$, as expected for a strong acid. ${ }^{32}$ By contrast, the $\mathrm{CVs}$ collected for 1 using an identical amount of TFA showed catalytic peak currents with an onset potential more positive than the $E_{\mathrm{Ni}^{\mathrm{II}} / \mathrm{I}}$ value and the catalytic peak potentials were at least $215 \mathrm{mV}$ more positive than that of the HER promoted by bare GC electrode in the absence of a catalyst (Figures 6a and S16). It is important to note that although the onset potentials were similar for $\mathbf{1}$ and the GC electrode, comparatively higher peak current densities were observed for $\mathbf{1}$ in the presence of identical amount of acid (Figure S16).

Furthermore, the CVs of 1 showed a new oxidative wave at around $-0.3 \mathrm{~V}$ with a peak current density $\sim 1 \mathrm{~mA} / \mathrm{cm}^{2}$ in the presence of a small amount of TFA $(4.35 \mathrm{mM})$ while scanning oxidatively after completing the cathodic scan (Figure 6b). Such peak current densities gradually diminished as the TFA concentration was increased up to $43.41 \mathrm{mM}$. Interestingly, both complexes 1 and $\mathbf{2}$ exhibit similar CVs under the same acid concentration (Table S1), suggesting a common HER electrocatalytic mechanism, or a rather rapid conversion of $\mathbf{2}$ into $\mathbf{1}$ in the presence of acid.
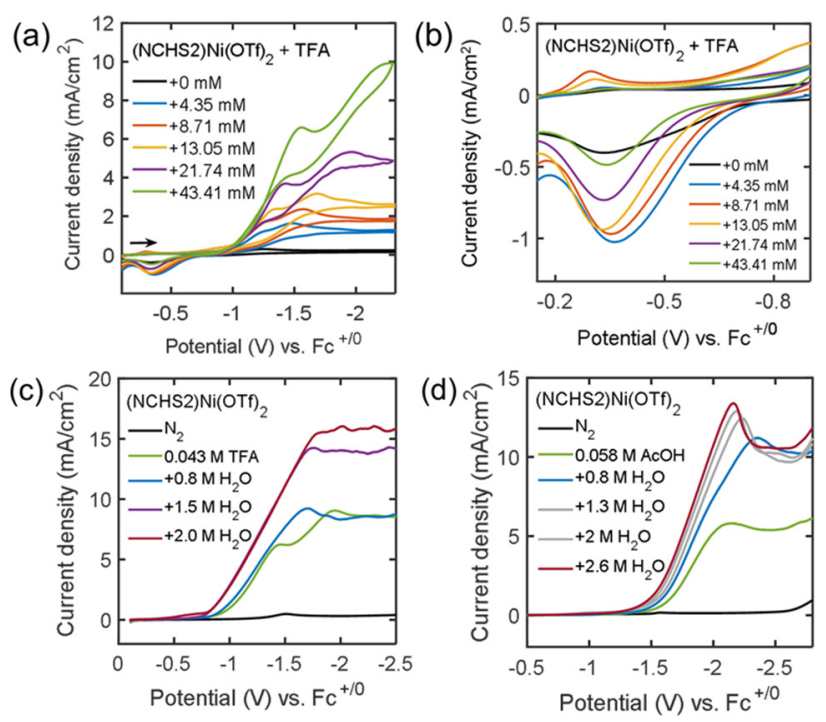

Figure 6. (a) CVs collected for $\mathbf{1}$ in the absence (black) and the presence of different concentrations of TFA $(4.35 \mathrm{mM}-43.41 \mathrm{mM})$, within the electrochemical window of (a) $0 \mathrm{~V}$ and $-2.4 \mathrm{~V}$, and (b) $-0.15 \mathrm{~V}$ and $-0.85 \mathrm{~V}$. Linear sweep voltammograms for $\mathbf{1}$ in the absence of acid 
(black), and the presence of (c) $0.043 \mathrm{M}$ TFA and (d) $0.058 \mathrm{M} \mathrm{AcOH}$ at different $\mathrm{H}_{2} \mathrm{O}$ concentrations (scan rate $=0.1 \mathrm{~V} / \mathrm{s}$ ).

Finally, the addition of $\mathrm{H}_{2} \mathrm{O}$ is common for HER studies as $\mathrm{H}_{2} \mathrm{O}$ can improve the proton supply and thus can enhance the reaction kinetics without compromising the thermodynamic limitations. ${ }^{26,32}$ Herein, the addition of $\mathrm{H}_{2} \mathrm{O}$ at different concentrations $(0.8-2 \mathrm{M})$, revealed plateau current densities for 1 at potentials lower than $-1.5 \mathrm{~V}$ in presence of $0.043 \mathrm{M}$ TFA (Figure 6c). Similar quasi-plateau current densities were also observed in presence of $0.058 \mathrm{M} \mathrm{AcOH}$ upon addition of $\mathrm{H}_{2} \mathrm{O}$, but at potentials lower than $-2 \mathrm{~V}$ (Figure 6d). Overall, these results strongly suggest that $\mathbf{1}$ is an efficient electrocatalyst to perform HER at low acid concentration using a moderate to weak acid in wet MeCN.

\section{Discussion}

Based on the electrochemical studies above, we propose that $\mathbf{1}$ follows an $\mathrm{E}_{1} \mathrm{C}_{1} \mathrm{E}_{2} \mathrm{C}_{2}$ electrochemical HER mechanism (Figure 7), where the first $\mathrm{E}_{1} \mathrm{C}_{1}$ steps include the conversion of 1 to 4 or 5 , as discussed above (Figure 4). The subsequent $\mathrm{E}_{2}$ step reduces 4 by $1 \mathrm{e}^{-}$to generate a $\mathrm{Ni}^{\mathrm{II}}$-hydride species $\mathbf{6}$, a common intermediate observed for molecular $\mathrm{Ni}$ based HER electrocatalysts. ${ }^{25,26}$ Importantly, herein the $\mathrm{Ni}^{\mathrm{II}}$-hydride intermediate is likely generated via a $\mathrm{Ni}^{\mathrm{I}} / \mathrm{N}^{\mathrm{III}}$ process, which is not common for the other reported Ni HER electrocatalysts (Figure 1b). Interestingly, the addition of 1 equiv TFA to the EPR sample of the chemically reduced 1 showed the rapid disappearance of one of the EPR species (Figure S37) that is tentatively assigned to the degradation of 4 or 5 ( $\operatorname{sim} 2$, Figure 5), whereas the other EPR species decayed more slowly, likely due to the increased stability of $\mathbf{3}$ in presence of protons. Overall, these results further support the proposed electrochemical mechanism (Figure 4), in which 1 can be reduced 
chemically/electrochemically to generate $\mathbf{3}$, followed by a Nernstian chemical step to yield $\mathbf{4}$ or $\mathbf{5}$, which are sensitive to the presence of protons in the organic solvent. Thus, the intermediates 4 and 5 behave similarly to the $\mathrm{Ni}$ center in the [NiFe]hydrogenase during the reduction of protons to $\mathrm{H}_{2}$.

Furthermore, protonation of 6 to yield $\mathrm{H}_{2}$ can be anticipated to proceed in two ways, either via a direct $1 \mathrm{H}^{+}$and $1 \mathrm{e}^{-}$reduction of 6 using stronger acids (e.g., TFA), or protonation of the pyridyl $\mathrm{N}$ atom of $\mathbf{6}$ first to form $\mathbf{7}$ - as indicated by the pre-catalytic wave in the presence of AcOH (Figure S17), ${ }^{45,46}$ followed by a $1 \mathrm{e}^{-}$reduction. Thus, the $\mathrm{H}_{2}$ evolution from 6 would close the HER catalytic cycle in the cathodic scan to generate $\mathbf{8}$, which can be further oxidized to $\mathbf{2}$ in the returning oxidative scan, as revealed by a small anodic wave at $-0.3 \mathrm{~V}$ observed in the $\mathrm{CV}$ (Figure 6b). Alternatively, 8 could regenerate $\mathbf{4}$ at higher acid concentrations, as suggested by the diminishing peak current densities at the anodic wave at $-0.3 \mathrm{~V}$ at higher TFA concentrations (Figure 6b). Overall, it is important to note that $\mathbf{1}$ follows a very selective ECEC electrochemical mechanism for HER that likely includes $\mathrm{Ni}^{\mathrm{I}}$ and $\mathrm{Ni}^{\mathrm{III}}$ intermediates, similar to what is observed for [NiFe] hydrogenases (Figure 1a) ${ }^{47}$ In addition, the C-H activation step of the NCHS2 ligand to generate the (NCS2) $\mathrm{Ni}^{\mathrm{II}}$ species 2 in situ seems to be essential to further stabilize the $\mathrm{Ni}^{\mathrm{I}}$ species for the HER step, as well as support any generated $\mathrm{Ni}^{\mathrm{III}}$ species that that are further stabilized by a Ni-C bond. Importantly, the ESI-MS analysis of the resulting solution from the HER electrocatalysis performed for $\mathbf{1}$ in $\mathrm{CD}_{3} \mathrm{CN}$ and in presence of $\mathrm{D}_{2} \mathrm{O}$ revealed the formation of the deuterium-labeled NCDS2 ligand, strongly supporting the activation of the $\mathrm{C}_{\mathrm{ipso}}-\mathrm{H}$ bond of NCHS2 ligand during the HER electrolysis process (Figures S39-S42). 


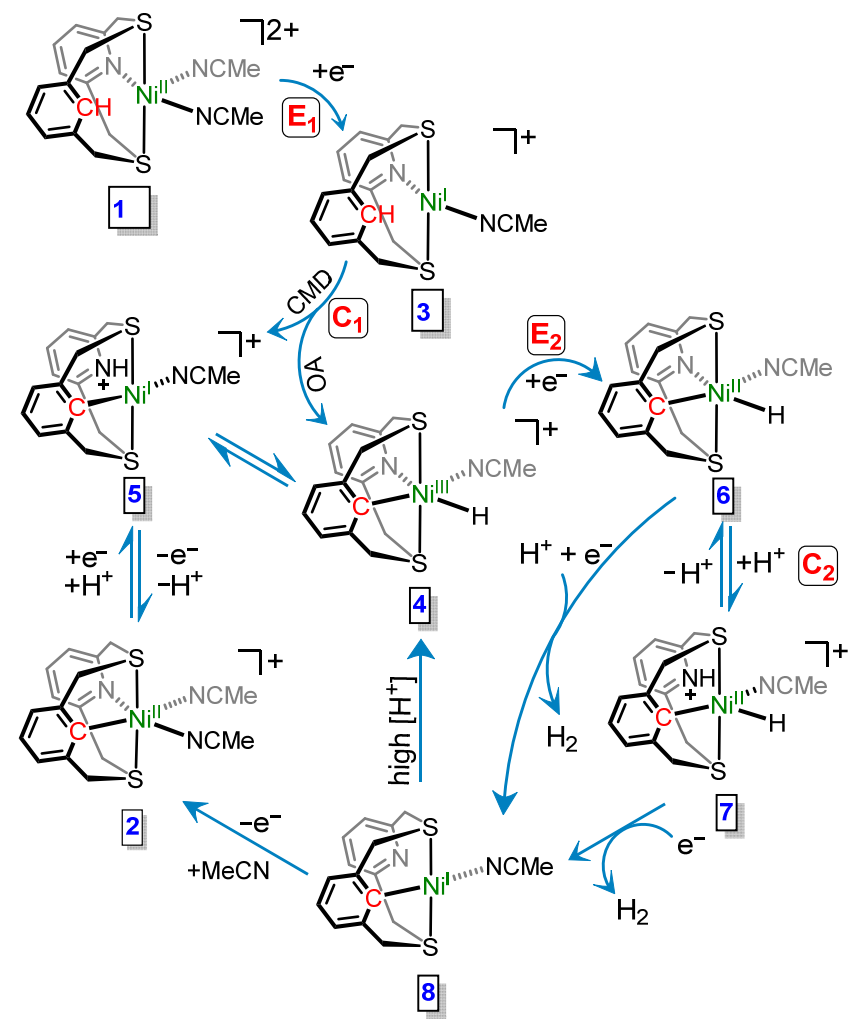

Figure 7. Proposed electrochemical HER mechanisms promoted by 1. CMD and OA indicate a concerted metalation-deprotonation and an oxidative addition process, respectively.

Further kinetic insights into the HER electrocatalysis by 1 were gained through foot-ofthe-wave analysis (FOWA, Figure S31) performed by subtracting the HER catalytic current due to the bare GC electrode in presence of the acid. For FOWA, it was assumed that $\mathbf{1}$ follows an overall electrochemical ECEC mechanism for HER and there is no catalyst degradation or substrate depletion during the diffusion-controlled electrochemical reactions. ${ }^{48,49}$ The slopes obtained from the linear fit at the lower range of $\left[1+\exp \left(\mathrm{f}\left(\mathrm{E}-\mathrm{E}_{1 / 2}\right)\right]^{-1}\right.$ of such FOWA (where $\mathrm{f}=$ $38.94 \mathrm{~V}^{-1}, \mathrm{E}$ is the applied potential, and $\mathrm{E}_{1 / 2}=E_{\mathrm{Ni}^{\mathrm{II} / \mathrm{I}}}$ ) provided similar pseudo-first-order rate constants $\left(k_{\text {FOWA }}\right.$, Table S2) for 1 at the different $\mathrm{H}_{2} \mathrm{O}$ concentrations (Figure 6c). Under these electrochemical conditions, the average maximum TOF value $\left(\mathrm{TOF}_{\max }=k_{F O W A}\right)$ was calculated 
as $(4.16 \pm 0.36) \times 10^{5} \mathrm{~s}^{-1}$ for $\mathbf{1}$ and corresponding to an overall second-order rate constant, $k_{1}\left(k_{1}\right.$ $\left.=k_{F O W A} /\left[\mathrm{H}^{+}\right]\right)$of $(9.67 \pm 0.85) \times 10^{6} \mathrm{M}^{-1} \mathrm{~s}^{-1}($ Table S2$)$.

The overpotential of the HER process, calculated using the Appel and Helm method, ${ }^{50}$ was found to be $490 \mathrm{mV}$ at $\mathrm{E}_{\mathrm{cat} / 2}$ for $\mathbf{1}$. Under these electrochemical conditions, chronoamperometric experiments carried out for $\mathbf{1}$ showed $220 \mathrm{mC}$ of total charge passed over 15 mins of electrolysis

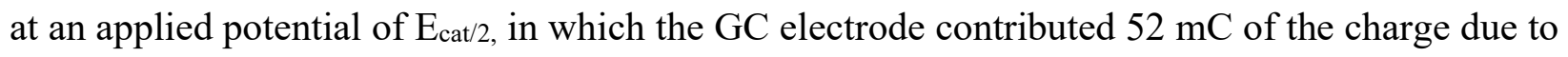
the background acid only reduction (Figure S28). Since the background charge due to the HER performed by the bare carbon electrode is significant, as expected for a strong acid, ${ }^{32}$ we have selected the applied potential for the controlled potential electrolysis to be $\sim \mathrm{E}_{\mathrm{cat}}$, since the background contribution increased at more negative potentials. Bulk electrolysis was also performed for $\mathbf{1}$ at the applied potential of $E_{\text {cat } / 2}$ using a carbon cloth electrode $\left(\operatorname{area}=1.5 \mathrm{~cm}^{2}\right)$ in the presence of $0.043 \mathrm{MTFA}+1.5 \mathrm{M} \mathrm{H}_{2} \mathrm{O}$ in $\mathrm{MeCN}$, to produce a large amount of $\mathrm{H}_{2}$ in the headspace of the electrochemical cell. The total charge passed over 1 hour of bulk electrolysis was 49.2 C, corresponding to 0.255 mmoles of estimated $\mathrm{H}_{2}$ (Figure S29). After the bulk electrolysis, 0.239 mmoles of $\mathrm{H}_{2}$ were detected by analyzing the headspace using gas chromatography, corresponding to a TON of 47.8 and an overall Faradaic efficiency (FE) for $\mathrm{H}_{2}$ formation of $94 \%$. Notably, this TON was calculated using the total moles of $\mathbf{1}$ in solution, rather than the actual concentration of the electroactive catalyst; moreover, catalyst $\mathbf{1}$ is still active and did not become inactivated after 1 hour of bulk electrolysis, and thus it is difficult to determine the true TON, which is expected to be much larger than 48. Although the background charge passed during the electrocatalytic HER process in the presence of the bare electrode is about $25 \%$ vs. the charge passed in the presence of complex $\mathbf{1}$, the faradaic efficiency of the background HER process is low $(\mathrm{FE}<25 \%)$ and does not contribute to more than $5-7 \%$ of the total $\mathrm{H}_{2}$ produced (Figure $\mathrm{S} 30$ ). 
To further benchmark 1, we have compared its catalytic Tafel plot to those of the previously reported molecular $\mathrm{Ni}^{\mathrm{II}} \mathrm{HER}$ electrocatalysts such as $\left[\left(\mathrm{NP}_{2}\right)_{2} \mathrm{Ni}\right]^{2+}$ and $\left[\left(\mathrm{NP}_{2}-\mathrm{PhBr}\right)_{2} \mathrm{Ni}\right]^{2+}$ in the presence of $[(\mathrm{DMF}) \mathrm{H}]^{+}$in wet $\mathrm{MeCN},{ }^{24,26}$ or $\left[\left(\mathrm{N}_{2} \mathrm{P}_{2}\right)_{2} \mathrm{Ni}\right]^{2+}$ in the presence of anilinium (Figure 8) ${ }^{25}$ Notably, the TOF $\max$ value of $\sim 400,000 \mathrm{~s}^{-1}$ obtained for $\mathbf{1}$ at a low TFA concentration $(0.043$ $\mathrm{M})$ in wet $\mathrm{MeCN}$ is 5 -fold and 100 -fold larger than for the reported $\left[\left(\mathrm{NP}_{2}\right)_{2} \mathrm{Ni}\right]^{2+}{ }^{24}$ and $\left[\left(\mathrm{NP}_{2}-\right.\right.$ $\left.\mathrm{PhBr})_{2} \mathrm{Ni}\right]^{2+}$ complexes, ${ }^{26}$ for which $[(\mathrm{DMF}) \mathrm{H}]^{+}$and $\mathrm{H}_{2} \mathrm{O}$ were used as the proton sources, respectively. A competitive HER electrocatalyst is $\left[\left(\mathrm{N}_{2} \mathrm{P}_{2}\right)_{2} \mathrm{Ni}\right]^{2+}$ in $\mathrm{MeCN}$ in the presence of $\geq 0.6$ $\mathrm{M}$ of anilinium as the proton source ${ }^{25}$ that shows a 8 -fold higher TOF $_{\max }$ than that of $\mathbf{1}$. However, considering that $[(\mathrm{DMF}) \mathrm{H}]^{+}$and anilinium are stronger acids in $\mathrm{MeCN}$ than TFA, it is impressive the 1 exhibits competitively higher TOFs for the HER process at low TFA concentrations $(\leq 0.043$ M). The overpotential associated with $\mathbf{1}$ is similar to that obtained for $\left[\left(\mathrm{NP}_{2}-\mathrm{PhBr}\right)_{2} \mathrm{Ni}^{2+}\right.$, yet it is $290 \mathrm{mV}$ lower than that of $\left[\left(\mathrm{NP}_{2}\right)_{2} \mathrm{Ni}^{2+}\right.$, which uses a stronger acid, $[(\mathrm{DMF}) \mathrm{H}]^{+}$. By contrast, $\left[\left(\mathrm{N}_{2} \mathrm{P}_{2}\right)_{2} \mathrm{Ni}\right]^{2+}$ preforms HER in the presence of $\leq 0.6 \mathrm{M}$ anilinium at a $350 \mathrm{mV}$ lower overpotential than that of $\mathbf{1}$, albeit anilinium is a stronger acid than TFA. Finally, the bio-inspired bimetallic $\left(\mathrm{S}_{2} \mathrm{P}_{2}\right) \mathrm{Ni}-\mathrm{FeCp}_{2}$ complex catalyzes electrochemical HER at a similar overpotential as $\left[\left(\mathrm{N}_{2} \mathrm{P}_{2}\right)_{2} \mathrm{Ni}\right]^{2+}$, yet the TOF is significantly lower than that of $\mathbf{1}^{27}$ 


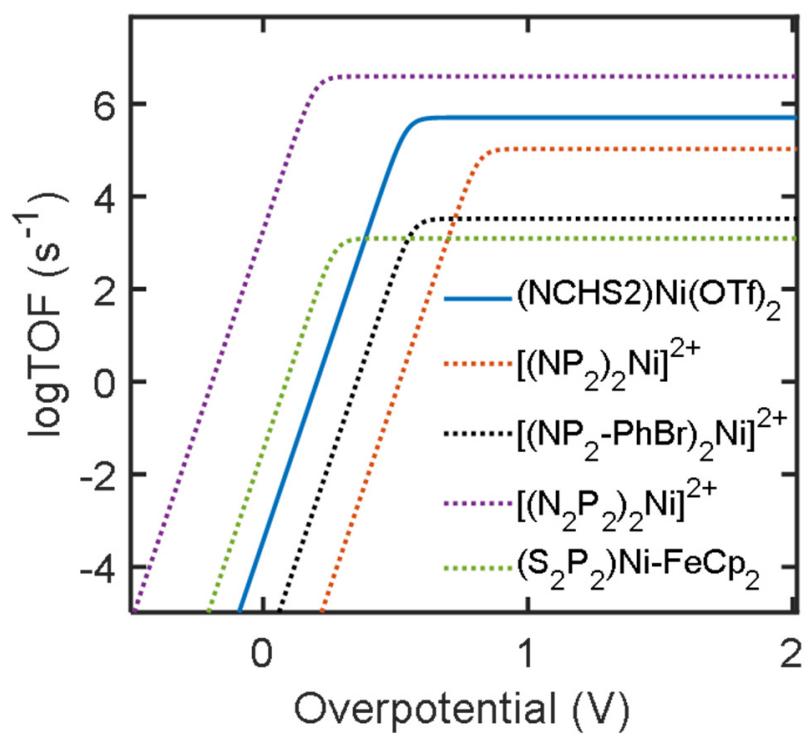

Figure 8. Comparative catalytic Tafel plots for 1 and reported $\mathrm{Ni}^{\mathrm{II}} \mathrm{HER}$ electrocatalysts (Figure 1b). Electrochemical conditions for 1 (blue): $0.043 \mathrm{M} \mathrm{TFA}+1.5 \mathrm{M} \mathrm{H}_{2} \mathrm{O}$ in $\mathrm{MeCN},\left[\left(\mathrm{NP}_{2}\right)_{2} \mathrm{Ni}^{2+}\right.$ (orange) and $\left[\left(\mathrm{NP}_{2}-\mathrm{PhBr}\right)_{2} \mathrm{Ni}\right]^{2+}$ (black): $[(\mathrm{DMF}) \mathrm{H}]^{+}(\geq 0.42 \mathrm{M})+\mathrm{H}_{2} \mathrm{O}(\geq 1.2 \mathrm{M})$ in $\mathrm{MeCN},{ }^{24,26}$ $\left[\left(\mathrm{N}_{2} \mathrm{P}_{2}\right)_{2} \mathrm{Ni}\right]^{2+}$ (purple): anilinium $(\leq 0.6 \mathrm{M})$ in $\mathrm{MeCN}^{25}$ and $\left(\mathrm{S}_{2} \mathrm{P}_{2}\right) \mathrm{Ni}-\mathrm{FeCp} 2$ (green): $\mathrm{AcOH}(0.05$ $\mathrm{M})$ in THF. ${ }^{27}$ The $\mathrm{TOF}_{\max }$ for the reported electrocatalysts were taken from their reported values, and overpotentials were calculated by correcting the standard thermodynamic potential, $E_{\mathrm{H}^{+} / \mathrm{H}_{2}}^{0}$ at the given $\mathrm{pK}_{\mathrm{a}}$ of the acid used in the non-aqueous electrolyte.

In conclusion, herein we report a novel bioinspired $\mathrm{Ni}^{\mathrm{II}}$ complex $(\mathrm{NCHS} 2) \mathrm{Ni}(\mathrm{OTf})_{2}$, 1(OTf)2, which is an efficient electrocatalyst for HER with turnover frequencies up to $400,000 \mathrm{~s}^{-}$ ${ }^{1}$ in the presence of low acid concentration and at a low overpotential of $490 \mathrm{mV}$, and compares favorably with the other reported Ni HER electrocatalysts. Importantly, the other Ni-based electrocatalysts are proposed to involve $\mathrm{Ni}^{0} / \mathrm{Ni}^{\mathrm{II}}$ intermediates during the HER process, whereas $\mathbf{1}$ follows a selective HER mechanism involving detectable $\mathrm{Ni}^{\mathrm{I}} / \mathrm{Ni}^{\mathrm{III}}$ intermediates and thus more closely mimics the intermediates observed in [NiFe] hydrogenases. In addition, the $\mathrm{C}-\mathrm{H}$ activation step of the NCHS2 ligand to generate the (NCS2) $\mathrm{Ni}^{\mathrm{II}}$ species in situ seems to be essential to promote the $\mathrm{Ni}^{\mathrm{I}}$ species as the key intermediate for the HER step, as well as support the generated $\mathrm{Ni}^{\mathrm{III}}$ species that are further stabilized by a $\mathrm{Ni}-\mathrm{C}$ bond. Overall, we consider that $\mathbf{1}$ can be viewed as a bioinspired, constrained geometry electrocatalyst that is a good functional model for the $\mathrm{Ni}$ 
center in $[\mathrm{NiFe}]$ hydrogenases and thus provides a new platform for HER electrocatalysis and heralds a new generation of bioinspired HER catalysts.

Supporting Information. Experimental details for the synthesis methodologies, spectroscopic characterization, supporting electrochemical data, and X-ray crystallographic data are available in the Supplementary Information. Crystallographic data for compounds NCHS2, 1, and $[(\mathrm{NCS} 2) \mathrm{Ni}(\mu-\mathrm{Br})]_{2}$ are available free of charge from the Cambridge Crystallographic Data Centre (CCDC) under deposition numbers 2053834, 2053836, and 2053837, respectively.

\section{AUTHOR INFORMATION}

\section{Corresponding Author}

*Department of Chemistry, University of Illinois-Urbana Champaign, $600 \mathrm{~S}$. Mathews Avenue, Urbana, IL, 61801, USA.

Email: $\underline{\text { mirica@illinois.edu }}$

ORCID

Liviu M. Mirica: 0000-0003-0584-9508

Soumalya Sinha: 0000-0002-6212-1102

Giang N. Tran: 0000-0003-0758-4136

Hanah Na: 0000-0002-0576-4806

\section{ACKNOWLEDGMENTS}

We thank the Department of Energy's BES Catalysis Science Program (DE-SC0006862) for financial support of the initial ligand synthesis work, and the National Science Foundation (CHE- 
1925751) for the subsequent reactivity studies. We thank Prof. Nigam P. Rath (Univ. of Missouri

- St. Louis) for obtaining the crystal structures of NCHS2 and 2, and Leonel Griego for discussions related to EPR data analysis. We also thank all the research facilities in the Department of Chemistry at the University of Illinois at Urbana-Champaign for their assistance.

\section{REFERENCES}

1. Lewis, N. S. \& Nocera, D. G. Powering the planet: Chemical challenges in solar energy utilization. Proc. Nat. Acad. Sci. USA 103, 15729-15735 (2006).

2. Nocera, D. G. The Artificial Leaf. Acc. Chem. Res. 45, 767-776 (2012).

3. Tard, C. \& Pickett, C. J. Structural and functional analogues of the active sites of the [Fe]-, [NiFe]-, and [FeFe]-hydrogenases. Chem. Rev. 109, 2245-2274 (2009).

4. Wang, M., Chen, L. \& Sun, L. Recent progress in electrochemical hydrogen production with earth-abundant metal complexes as catalysts. Energy Environ. Sci. 5, 6763-6778 (2012).

5. Simmons, T. R., Berggren, G., Bacchi, M., Fontecave, M. \& Artero, V. Mimicking hydrogenases: From biomimetics to artificial enzymes. Coord. Chem. Rev. 270-271, 127-150 (2014).

6. Bullock, R. M. \& Helm, M. L. Molecular Electrocatalysts for Oxidation of Hydrogen Using Earth-Abundant Metals: Shoving Protons Around with Proton Relays. Acc. Chem. Res. 48, 2017-2026 (2015).

7. Xu, T., Chen, D. \& Hu, X. Hydrogen-activating models of hydrogenases. Coord. Chem. Rev. 303, 32-41 (2015).

8. Ahmed, M. E. \& Dey, A. Recent developments in bioinspired modelling of [NiFe]- and [FeFe]-hydrogenases. Curr. Opin. Electrochem. 15, 155-164 (2019).

9. Vincent, K. A., Parkin, A. \& Armstrong, F. A. Investigating and exploiting the electrocatalytic properties of hydrogenases. Chem. Rev. 107, 4366-4413 (2007).

10. Cracknell, J. A., Vincent, K. A. \& Armstrong, F. A. Enzymes as working or inspirational electrocatalysts for fuel cells and electrolysis. Chem. Rev. 108, 2439-2461 (2008).

11. Madden, C. et al. Catalytic Turnover of [FeFe]-Hydrogenase Based on Single-Molecule Imaging. J. Am. Chem. Soc. 134, 1577-1582 (2012).

12. Shafaat, H. S. in Comprehensive Coordination Chemistry III (eds Edwin C. Constable, Gerard Parkin, \& Lawrence Que Jr) 707-730 (Elsevier, 2021).

13. Whitehead, J. P., Gurbiel, R. J., Bagyinka, C., Hoffman, B. M. \& Maroney, M. J. The hydrogen binding site in hydrogenase: $35-\mathrm{GHz}$ ENDOR and XAS studies of the nickel-C (reduced and active form) and the Ni-L photoproduct. J. Am. Chem. Soc. 115, 5629-5635 (1993).

14. De Lacey, A. L., Fernandez, V. M., Rousset, M. \& Cammack, R. Activation and inactivation of hydrogenase function and the catalytic cycle: spectroelectrochemical studies. Chem. Rev. 107, 4304-4330 (2007).

15. Siegbahn, P. E., Tye, J. W. \& Hall, M. B. Computational studies of [NiFe] and [FeFe] hydrogenases. Chem. Rev. 107, 4414-4435 (2007). 
16. Lubitz, W., Ogata, H., Rudiger, O. \& Reijerse, E. Hydrogenases. Chem. Rev. 114, 4081-4148 (2014).

17. Ogata, H. et al. Hydride bridge in [NiFe]-hydrogenase observed by nuclear resonance vibrational spectroscopy. Nat. Commun. 6, 7890 (2015).

18. Hidalgo, R., Ash, P. A., Healy, A. J. \& Vincent, K. A. Infrared Spectroscopy During Electrocatalytic Turnover Reveals the Ni-L Active Site State During H2 Oxidation by a NiFe Hydrogenase. Angew. Chem., Int. Ed. 54, 7110-7113 (2015).

19. Murphy, B. J. et al. Discovery of Dark pH-Dependent H+ Migration in a [NiFe]-Hydrogenase and Its Mechanistic Relevance: Mobilizing the Hydrido Ligand of the Ni-C Intermediate. $J$. Am. Chem. Soc. 137, 8484-8489 (2015).

20. Schilter, D., Camara, J. M., Huynh, M. T., Hammes-Schiffer, S. \& Rauchfuss, T. B. Hydrogenase Enzymes and Their Synthetic Models: The Role of Metal Hydrides. Chem. Rev. 116, 8693-8749 (2016).

21. Gu, N. X., Oyala, P. H. \& Peters, J. C. H2 Evolution from a Thiolate-Bound Ni(III) Hydride. J. Am. Chem. Soc. 142, 7827-7835 (2020).

22. Gentil, S. et al. Carbon-Nanotube-Supported Bio-Inspired Nickel Catalyst and Its Integration in Hybrid Hydrogen/Air Fuel Cells. Angew. Chem., Int. Ed. 56, 1845-1849 (2017).

23. Gentil, S. et al. A Nanotube-Supported Dicopper Complex Enhances Pt-free Molecular H2/Air Fuel Cells. Joule 3, 2020-2029 (2019).

24. Helm, M. L., Stewart, M. P., Bullock, R. M., DuBois, M. R. \& DuBois, D. L. A Synthetic Nickel Electrocatalyst with a Turnover Frequency Above 100,000 s(-1) for H-2 Production. Science 333, 863-866 (2011).

25. Rountree, E. S. \& Dempsey, J. L. Potential-Dependent Electrocatalytic Pathways: Controlling Reactivity with $\mathrm{pK}(\mathrm{a})$ for Mechanistic Investigation of a Nickel-Based Hydrogen Evolution Catalyst. J. Am. Chem. Soc. 137, 13371-13380 (2015).

26. Wiese, S. et al. Hydrogen Production Using Nickel Electrocatalysts with Pendant Amines: Ligand Effects on Rates and Overpotentials. ACS Catal. 3, 2527-2535 (2013).

27. Gan, L. et al. A nickel phosphine complex as a fast and efficient hydrogen production catalyst. J. Am. Chem. Soc. 137, 1109-1115 (2015).

28. Ott, S., Kritikos, M., Akermark, B., Sun, L. \& Lomoth, R. A biomimetic pathway for hydrogen evolution from a model of the iron hydrogenase active site. Angew Chem Int Ed Engl 43, 1006-1009 (2004).

29. Schwartz, L. et al. Iron hydrogenase active site mimic holding a proton and a hydride. Chem. Comm., 520-522 (2006).

30. Lawrence, J. D., Li, H., Rauchfuss, T. B., Bénard, M. \& Rohmer, M.-M. Diiron Azadithiolates as Models for the Iron-Only Hydrogenase Active Site: Synthesis, Structure, and Stereoelectronics. Angew. Chem., Int. Ed. 40, 1768-1771 (2001).

31. Barton, B. E., Olsen, M. T. \& Rauchfuss, T. B. Aza- and oxadithiolates are probable proton relays in functional models for the [FeFe]-hydrogenases. J. Am. Chem. Soc. 130, 16834-16835 (2008).

32. McCarthy, B. D., Martin, D. J., Rountree, E. S., Ullman, A. C. \& Dempsey, J. L. Electrochemical Reduction of Brønsted Acids by Glassy Carbon in AcetonitrileImplications for Electrocatalytic Hydrogen Evolution. Inorg. Chem. 53, 8350-8361 (2014).

33. Passard, G., Dogutan, D. K., Qiu, M., Costentin, C. \& Nocera, D. G. Oxygen Reduction Reaction Promoted by Manganese Porphyrins. ACS Catal. 8, 8671-8679 (2018). 
34. Zhou, W., Zheng, S. A., Schultz, J. W., Rath, N. P. \& Mirica, L. M. Aromatic Cyanoalkylation through Double C-H Activation Mediated by Ni(III). J. Am. Chem. Soc. 138, 5777-5780 (2016).

35. Zhou, W., Rath, N. P. \& Mirica, L. M. Oxidatively-induced aromatic cyanation mediated by Ni(III). Dalton Trans. 45, 8693-8695 (2016).

36. Bard, A. J. Fundamentals and applications. 2, 580 (2001).

37. Savéant, J.-M. Elements of Molecular and Biomolecular Electrochemistry: An Electrochemical Approach to Electron Transfer Chemistry. pp 7- 52 (Wiley: New York, 2006, pp 7-52).

38. Elgrishi, N. et al. A Practical Beginner's Guide to Cyclic Voltammetry. J. Chem. Educ. 95, 197-206 (2018).

39. Savéant, J.-M. \& Costentin, C. Elements of Molecular and Biomolecular Electrochemistry: An Electrochemical Approach to Electron Transfer Chemistry. 2nd edn, (2019).

40. Richburg, C. S. \& Farnum, B. H. Influence of Pyridine on the Multielectron Redox Cycle of Nickel Diethyldithiocarbamate. Inorg. Chem. 58, 15371-15384 (2019).

41. Lapointe, D. \& Fagnou, K. Overview of the Mechanistic Work on the Concerted MetallationDeprotonation Pathway. Chem. Lett. 39, 1118-1126 (2010).

42. van Gastel, M. et al. Electronic structure of a binuclear nickel complex of relevance to [NiFe] hydrogenase. Inorg. Chem. 47, 11688-11697 (2008).

43. Perotto, C. U. et al. Heterobimetallic [NiFe] Complexes Containing Mixed CO/CN- Ligands: Analogs of the Active Site of the [NiFe] Hydrogenases. Inorg. Chem. 57, 2558-2569 (2018).

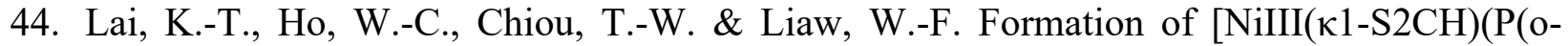
C6H3-3-SiMe3-2-S)3)]- via CS2 Insertion into Nickel(III) Hydride Containing [NiIII(H)(P(o-C6H3-3-SiMe3-2-S)3)]-. Inorg. Chem. 52, 4151-4153 (2013).

45. Sinha, S. \& Warren, J. J. Unexpected Solvent Effect in Electrocatalytic CO2 to CO Conversion Revealed Using Asymmetric Metalloporphyrins. Inorg. Chem. 57, 12650-12656 (2018).

46. Costentin, C., Passard, G., Robert, M. \& Savéant, J.-M. Pendant Acid-Base Groups in Molecular Catalysts: H-Bond Promoters or Proton Relays? Mechanisms of the Conversion of $\mathrm{CO} 2$ to $\mathrm{CO}$ by Electrogenerated Iron(0)Porphyrins Bearing Prepositioned Phenol Functionalities. J. Am. Chem. Soc. 136, 11821-11829 (2014).

47. Das, R., Neese, F. \& van Gastel, M. Hydrogen evolution in [NiFe] hydrogenases and related biomimetic systems: similarities and differences. Phys. Chem. Chem. Phys. 18, 24681-24692 (2016).

48. Costentin, C. \& Savéant, J.-M. Multielectron, Multistep Molecular Catalysis of Electrochemical Reactions: Benchmarking of Homogeneous Catalysts. ChemElectroChem 1, 1226-1236 (2014).

49. Artero, V. \& Saveant, J.-M. Toward the rational benchmarking of homogeneous H2-evolving catalysts. Energy Environ. Sci. 7, 3808-3814 (2014).

50. Appel, A. M. \& Helm, M. L. Determining the Overpotential for a Molecular Electrocatalyst. ACS Catal. 4, 630-633 (2014).

51. Pavlishchuk, V. V. \& Addison, A. W. Conversion constants for redox potentials measured versus different reference electrodes in acetonitrile solutions at $25^{\circ} \mathrm{C}$. Inorg. Chim. Acta 298, 97-102 (2000). 


\section{Table of Contents Graphic}

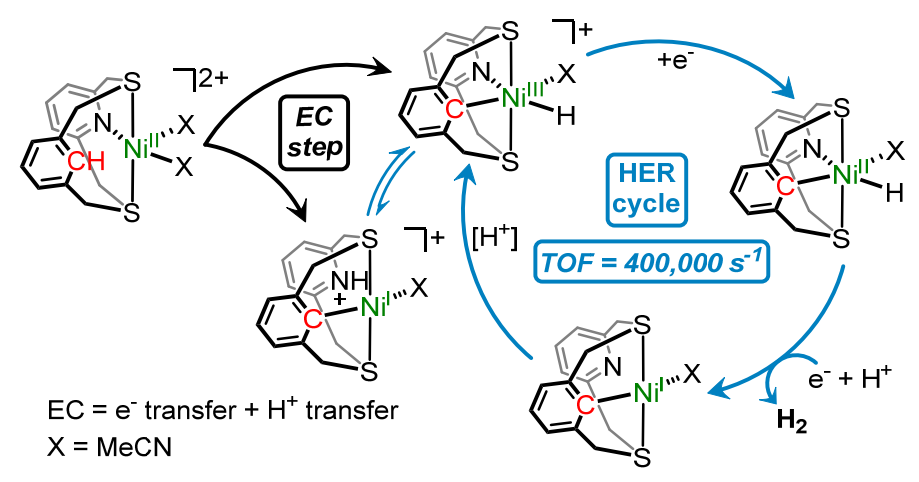

\section{Synopsis}

A bioinspired, constrained geometry (NCS2)Ni(II) electrocatalyst that can perform the hydrogen evolution reaction (HER) with very high turnover frequency at a low overpotential in the presence of low acid concentration is reported, and the proposed HER mechanism involves organometallic intermediates and $\mathrm{Ni}(\mathrm{I}) / \mathrm{Ni}(\mathrm{III})$ species. 